\title{
Less is more, now more than ever
}

\author{
Christine Soong (D) ,' Karen B Born, ${ }^{2,3}$ Wendy Levinson ${ }^{4}$
}

${ }^{1} \mathrm{GIM}$, Mount Sinai Hospital Toronto, Ontario, Canada ${ }^{2}$ Institute of Health Policy, Management and Evaluation, University of Toronto Faculty of Medicine, Toronto, Ontario, Canada

${ }^{3}$ Medicine, St. Michael's Hospital, Toronto, Ontario, Canada

${ }^{4}$ Deparment of Medicine, University of Toronto, Toronto, Ontario, Canada

\section{Correspondence to}

Dr Christine Soong, GIM, Mount Sinai Hospital, Toronto, ON M5G 1X5, Canada;

christine.soong@utoronto.ca

Received 30 April 2020 Accepted 8 May 2020 Published Online First 22 May 2020

\section{Check for updates}

(C) Author(s) (or their employer(s)) 2021. No commercial re-use. See rights and permissions. Published by BMJ.

To cite: Soong C, Born KB, Levinson W. BMJ Qual Saf 2021;30:56-58.
Our society and health systems have been upended by COVID-19. The search for a magic bullet is desperately being sought by decision makers and the public. Yet, aside from the early availability of a diagnostic test, there remains limited evidence that laboratory or imaging tests can accurately predict clinical deterioration beyond that afforded by basic vital signs. There are currently some therapies undergoing intensive investigation yet remain premature for widespread adoption, leaving clinicians and patients feeling frustrated and helpless. It is precisely at a time of crisis that clinicians should embrace that 'less is more' and consider that 'more' medical interventions can result in harm to patients and waste of limited healthcare system resources.

Many in the scientific and clinician community have pivoted to focus on a singular goal: advancing evidence on how to care for patients with COVID19. Importantly, there are voices within the research community urging that the scientific method should not be cast aside due to the urgency of the pandemic. ${ }^{1}$ Similarly, clinical reasoning and evidence-based medicine should not be disregarded in this crisis. ${ }^{2}$ Significant harms can arise when practices are adopted without scientific evaluation beyond evidence at the level of case series. $^{34}$

Despite the lack of proven care pathways and diagnostic or therapeutic interventions, there is widespread early adoption of practices that would not under normal circumstances be incorporated into clinical practice. This rush to unnecessary, unproven and off-label treatments can be explained in part by cognitive biases which have been previously described as drivers of overuse. ${ }^{5}$ The cognitive bias of the 'therapeutic illusion' is a common pitfall of modern medicine, where clinicians overestimate the benefit of treatments and believe in the effectiveness of medical interventions and tools in spite of evidence that they are futile or make no difference. ${ }^{6}$ Pressures from patients and families, colleagues and clinicians themselves who wish to 'do something' are amplified by the pandemic. It is humbling and indeed challenging for physicians to not have a care approach that offers any meaningful change to clinical outcomes. Given the highly infectious nature of COVID-19, there is added urgency as many patients are healthcare workers, having contracted the virus on the front lines. This element further clouds clinical judgement with emotions of fear, helplessness and anxiety.

The drive to 'do something' in caring for patients with COVID-19 is illustrative of these cognitive biases but conflicts with the urgent need for conservative approaches. Doing less in treating COVID-19 first protects clinicians and patients from harm, conserves limited healthcare resources and supports rigorous research methods.

Now more than ever, there is a recognition that the supply of healthcare resources sometimes taken for granted, such as personal protective equipment (PPE), laboratory services and medication, are limited and need to be used wisely. At the best of times, repeat laboratory testing or chest imaging for clinically stable hospitalised inpatients wastes resources and offers no clinical value and can harm patients. ${ }^{7-9}$ Yet, repeat routine testing appears to be common clinical practice for non-critically ill patients with COVID-19 in many jurisdictions with questionable impact on management. ${ }^{10}$ Not only does this potentially harm vulnerable patients but also it wastes limited laboratory resources and exposes clinicians performing routinely ordered tests to potential infection. Importantly, more direct patient contact exposes clinicians to COVID-19 with each clinical encounter and uses globally scarce PPE. 
Choosing Wisely released a list of COVID-19specific international recommendations for the public and clinicians. ${ }^{11}$ There are recommendations for both groups against the use of unproven and non-evidence-based treatments, with the rationale that this can cause harm and waste limited resources. Each day, there are new reports, speculation from political leaders of potential treatments and conflicting evidence around off-label treatments for COVID-19, such as anticoagulation without demonstrated thrombotic disease, chloroquine, hydroxychloroquine, azithromycin, zinc and remdesivir. ${ }^{12}$ Some of these are reasonably explained by fear: fear that doing nothing poses a greater harm than adoption of any promising therapies, even those that are unproven. However, history has shown us that this non-evidence-based approach, in addition to being ineffective, can actually harm patients most susceptible to adverse effects. ${ }^{13} 14$ Even if the potential gains outweigh documented harms, there are downstream and broader societal impacts to adopting unproven treatments. This has been seen in shortages of hydroxychloroquine and chloroquine due to overuse and patients stockpiling them in fear of shortages. Patients who regularly take these medications for lupus may risk suboptimal disease control if these medications are not available. ${ }^{15}$

Another driver contributing to the "do now, study later' approach is the cognitive bias of the 'bandwagon effect', where an unproven but popular idea gains widespread traction. The explosive interest in convalescent plasma as a potential treatment for severely ill patients with COVID-19 is an example of this. An uncontrolled case series of five critically ill patients in China receiving convalescent plasma was published in March 2020. ${ }^{16}$ The preliminary findings were subsequently amplified by media and social media and have driven desperate families to search for plasma donors and institutions willing to provide this experimental treatment. Importantly, the safety and efficacy of such approaches outside of a clinical trial are limited. Treatment approaches to COVID-19 are also challenged by ambiguity bias related to the unknowns of a relatively new infectious agent and a sense of urgency.

While the pandemic and its full lethality is a recent shock to healthcare systems globally, expert projections suggest this new virus is here to stay in the near-term. As healthcare systems and providers shift from the sprint to marathon approach to dealing with COVID-19, there is a need for a reckoning with unproven and wasteful treatment approaches. Choosing Wisely campaigns have influenced physician practice and public awareness of overuse since the campaign was launched in the USA. There is evidence of healthcare systems and providers making substantial practice changes to reduce overuse and harm to patients. ${ }^{17}$ The COVID-19 pandemic presents challenges of high patient volumes and acuity, clinical uncertainty, public pressures and scrutiny, coupled with a reduced healthcare workforce. In the 'new normal' state of constrained healthcare resources, less is more, now more than ever.

Twitter Christine Soong@christinesoong and Karen B Born @bornk

Contributors All authors contributed to the design, drafting and revisions of this paper.

Funding The authors have not declared a specific grant for this research from any funding agency in the public, commercial or not-for-profit sectors.

Competing interests None declared.

Patient consent for publication Not required.

Provenance and peer review Not commissioned; internally peer reviewed.

Data availability statement There are no data in this work.

ORCID iD

Christine Soong http://orcid.org/0000-0002-1397-9671

\section{REFERENCES}

1 London AJ, Kimmelman J. Against pandemic research exceptionalism. Science 2020;368:476-7.

2 Rice TW, Janz DR. In defense of evidence-based medicine for the treatment of COVID-19 ARDS. Ann Am Thorac Soc 2020. doi:10.1513/AnnalsATS.202004-325IP

3 Borba MGS, Val FFA, Sampaio VS, et al. Effect of high vs low doses of chloroquine diphosphate as adjunctive therapy for patients hospitalized with severe acute respiratory syndrome coronavirus 2 (SARS-CoV-2) infection. JAMA Netw Open 2020;3:e208857.

4 Ferner RE, Aronson JK. Chloroquine and hydroxychloroquine in covid-19. BMJ 2020;369:m1432.

5 Scott IA, Soon J, Elshaug AG, et al. Countering cognitive biases in minimising low value care. Med J Aust 2017;206:407-11.

6 Casarett D. The Science of Choosing Wisely--Overcoming the Therapeutic Illusion. N Engl J Med 2016;374:1203-5.

7 van Walraven C, Naylor CD. Do we know what inappropriate laboratory utilization is? A systematic review of laboratory clinical audits. JAMA 1998;280:550-8.

8 Thavendiranathan P, Bagai A, Ebidia A, et al. Do blood tests cause anemia in hospitalized patients? J Gen Intern Med $2005 ; 20: 520-4$.

9 Chahine-Malus N, Stewart T, Lapinsky SE, et al. Utility of routine chest radiographs in a medical-surgical intensive care unit: a quality assurance survey. Crit Care 2001;5:271-5.

10 Rodriguez-Morales AJ, Cardona-Ospina JA, GutiérrezOcampo E, et al. Clinical, laboratory and imaging features of COVID-19: a systematic review and meta-analysis. Travel Med Infect Dis 2020;101623.

11 Canada CW. Choosing wisely Canada COVID-19 recommendations.

12 Sanders JM, Monogue ML, Jodlowski TZ, et al. Pharmacologic treatments for coronavirus disease 2019 (COVID-19). JAMA 2020.

13 Arabi YM, Shalhoub S, Mandourah Y, et al. Ribavirin and interferon therapy for critically ill patients with middle East respiratory syndrome: a multicenter observational study. Clin Infect Dis 2020;70:1837-44. 


\section{Viewpoint}

14 Morra ME, Van Thanh L, Kamel MG, et al. Clinical outcomes of current medical approaches for middle East respiratory syndrome: a systematic review and meta-analysis. Rev Med Virol 2018;28:e1977.

15 Jakhar D, Kaur I. Potential of chloroquine and hydroxychloroquine to treat COVID-19 causes fears of shortages among people with systemic lupus erythematosus. Nat Med 2020;26:632.

16 Shen C, Wang Z, Zhao F, et al. Treatment of 5 critically ill patients with COVID-19 with convalescent plasma. JAMA 2020;323:1582.

17 Born K, Kool T, Levinson W. Reducing overuse in healthcare: advancing choosing wisely. BMJ 2019;367:16317. 